The World's Greatest Ship-The "Olympic"-a 60,00O-ton Vessel

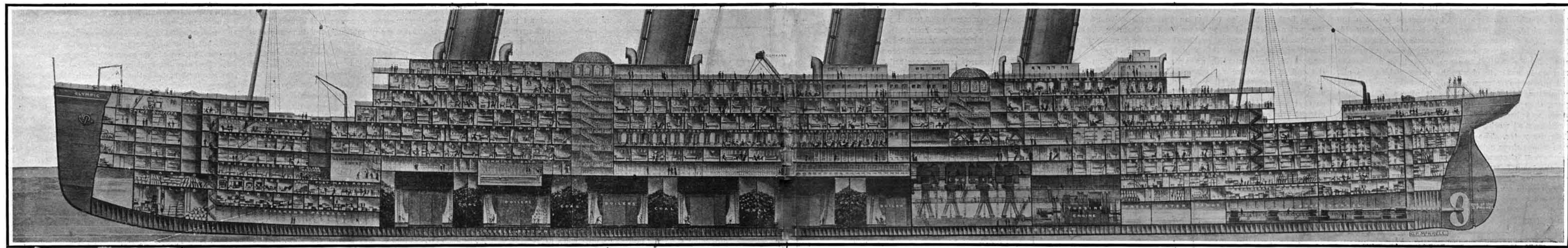

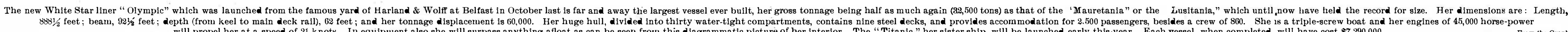
THE WORLD'S REATEST SHIP.

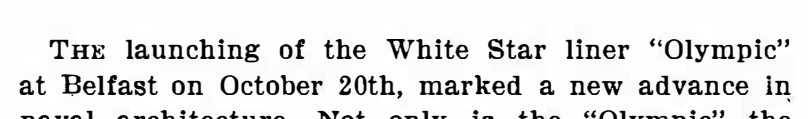

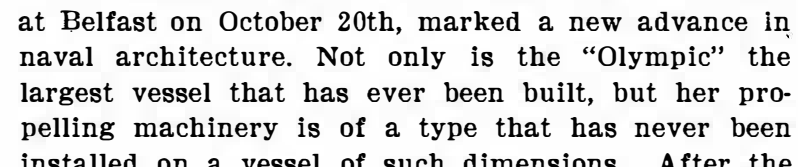

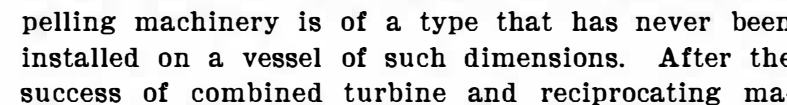

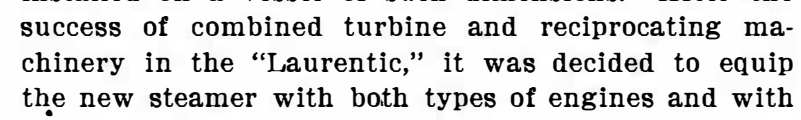

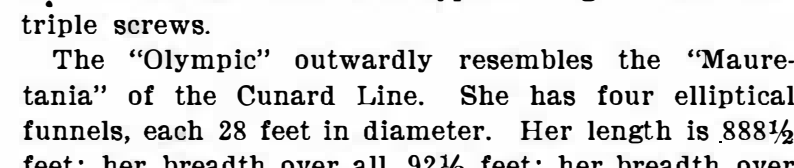

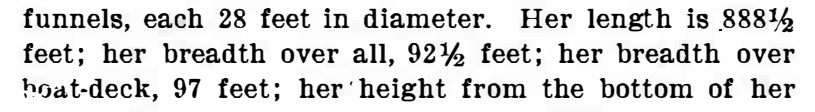

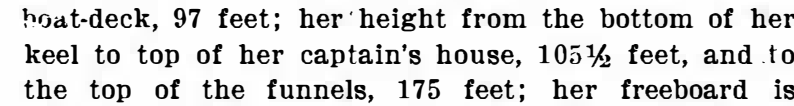

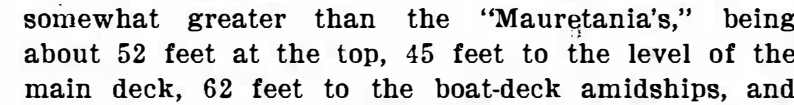

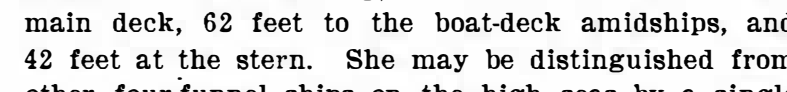

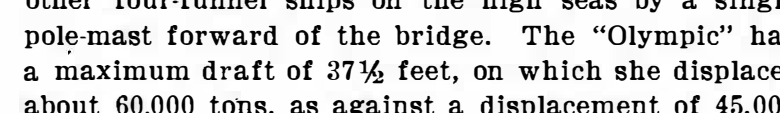

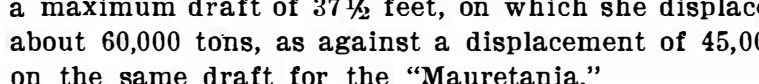

\section{The Structure of Metals}

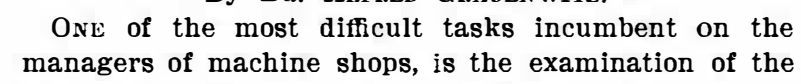

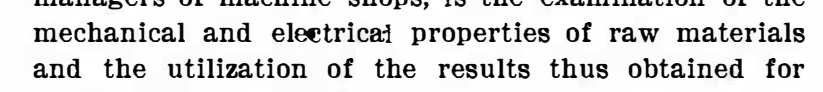
In the electrical industryy this task, because of the
pecular condititions of the case, becomes especially

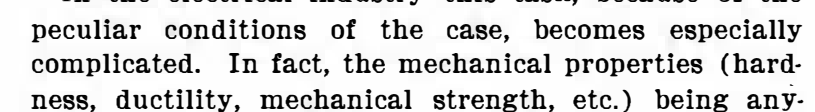

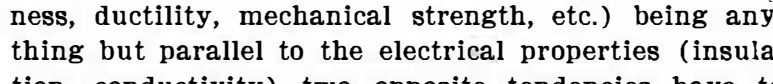

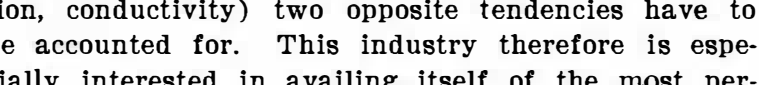

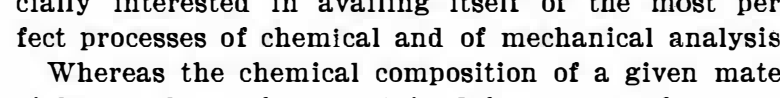
rial can almays be ascertaned by means ot a more
or less complicated analysis, the thermal processes

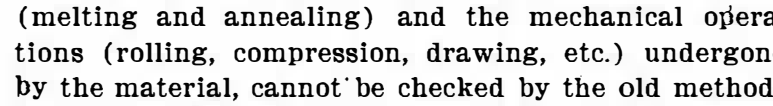

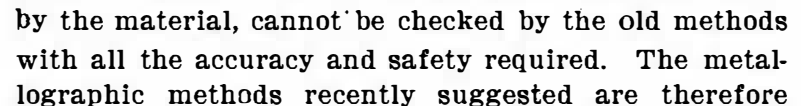

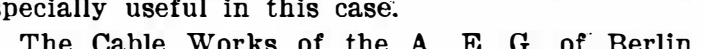

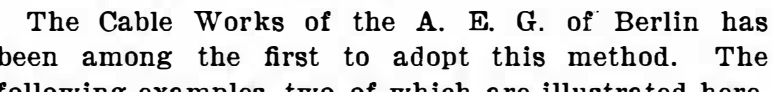

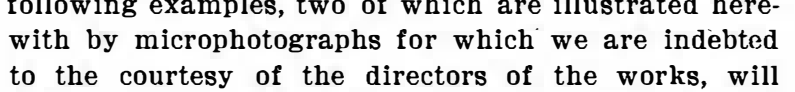

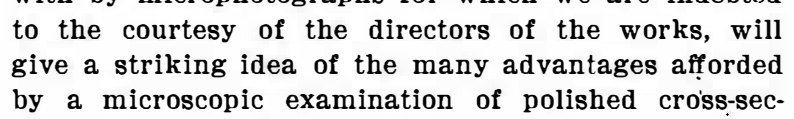

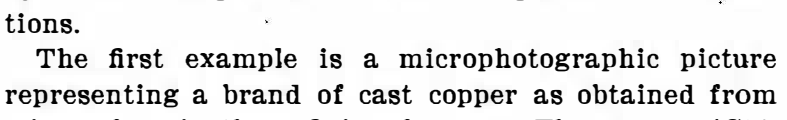

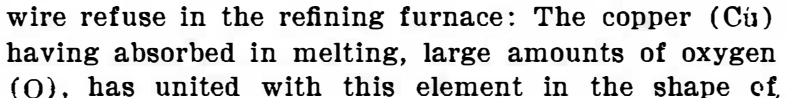

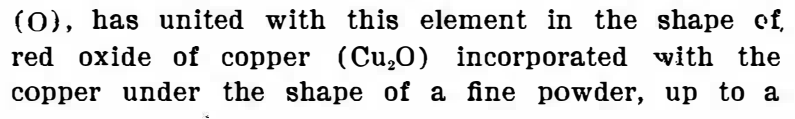

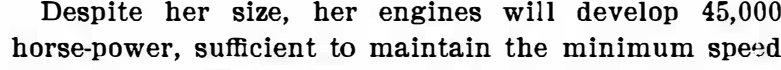

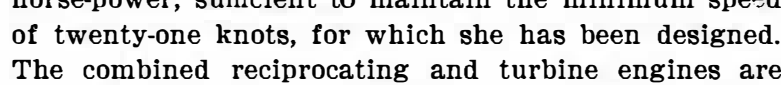

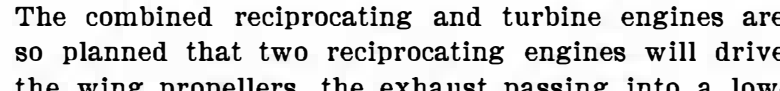

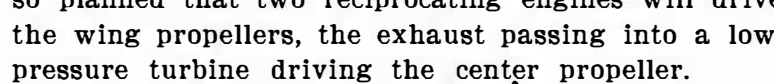

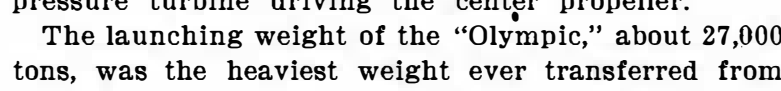

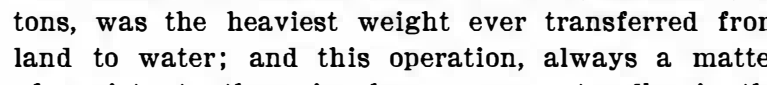

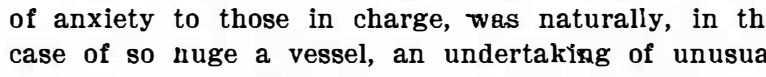
Importance. The method of launching was very silum
ple. The vessel was hald on the ways by hyyraulic trizgers, which were relasede by the mere opening of
a valve, in order that the vast structurer might glide

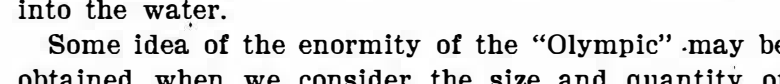
some of the parts that entered into her construccioio
Her rudder the castings comprising the stern trame, rudder, and

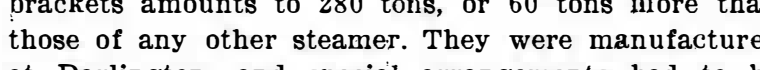

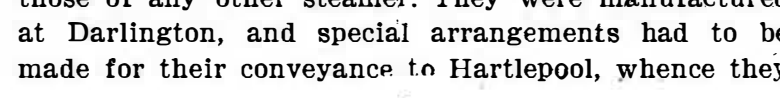

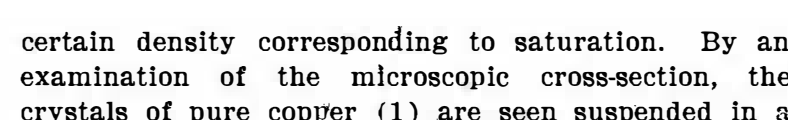

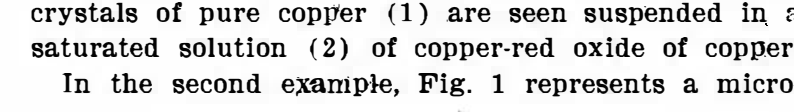

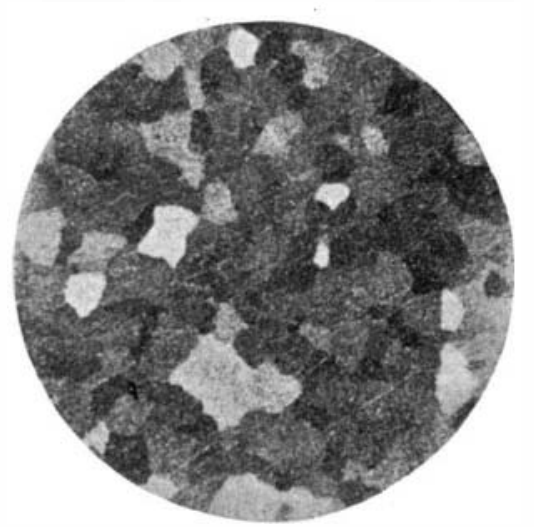

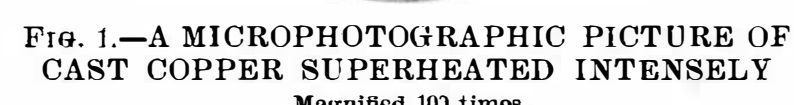

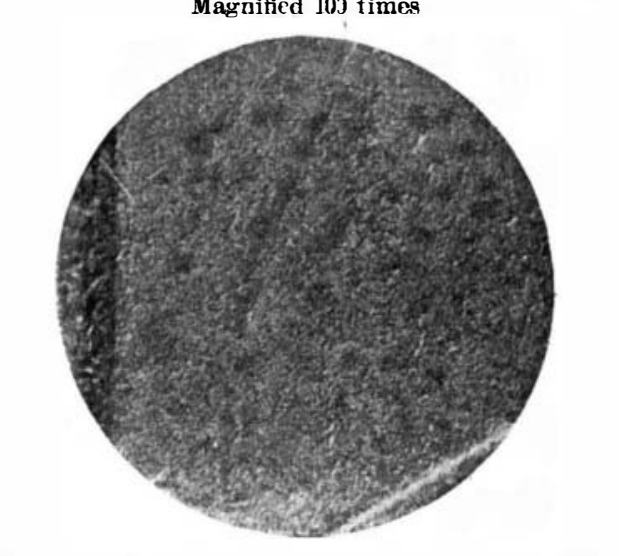

Frg. 2.-STRUCTURR OF SAME SPECIMEN
WHEN NON-MAGGETIC

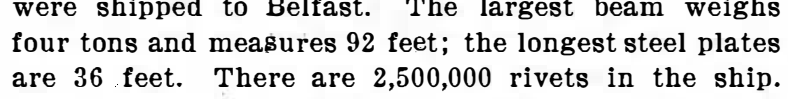

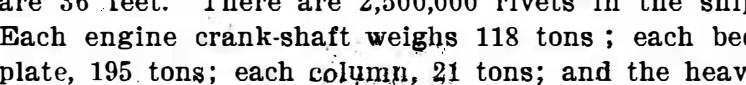

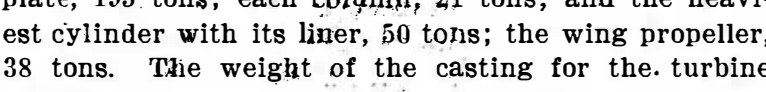

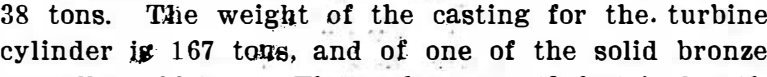

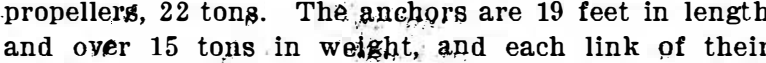

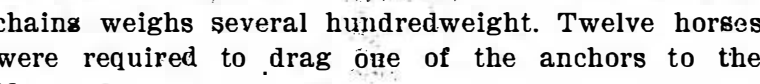

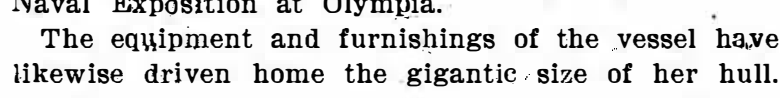

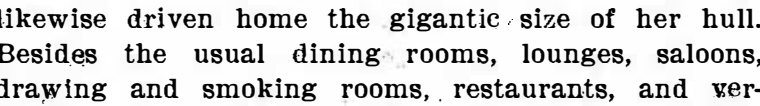

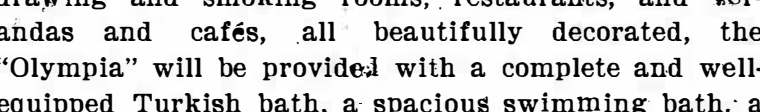

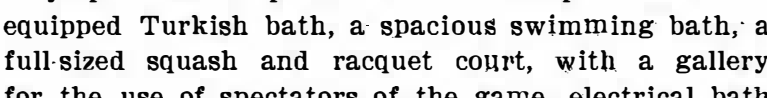

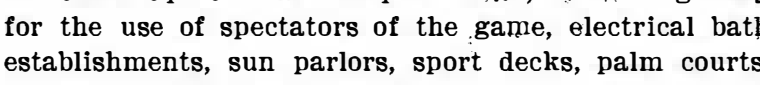

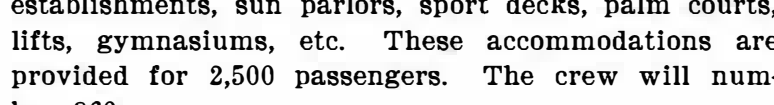

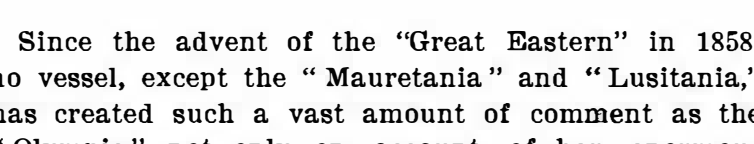

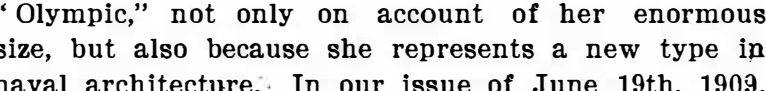

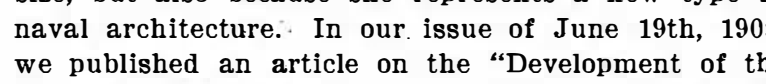

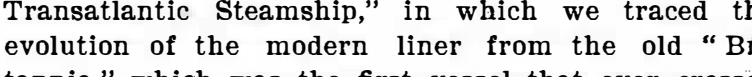
the Attantic on a regular schedule, to the resees

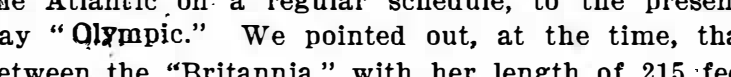

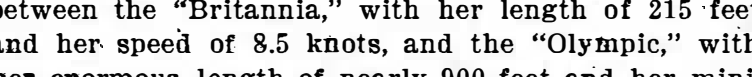

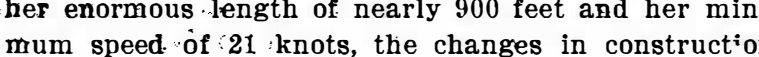
and in propenting machinery have been remarkable " "ritiannia" saw the ad vent of the "do a.vessel with a length of 275 feet and a speed in 1855 , with a length of 385 teet and a speed 0

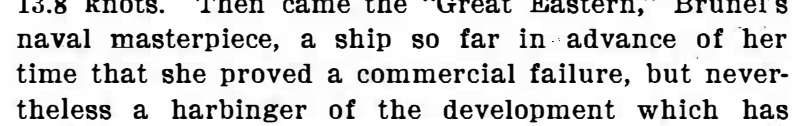

photographic pitcture or cast copper in which the per.
centage of

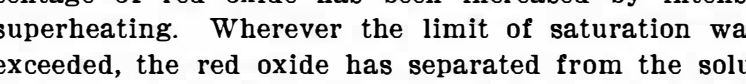

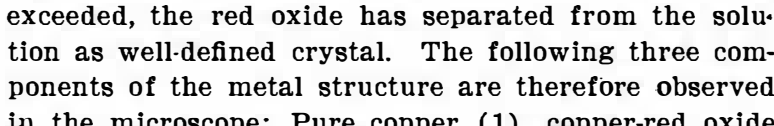

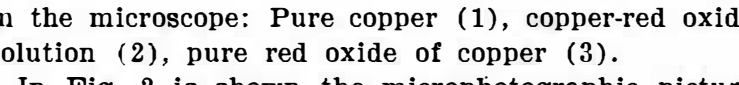

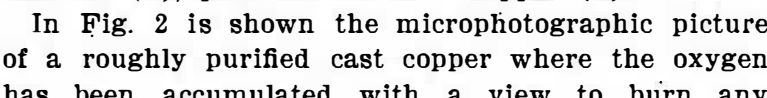

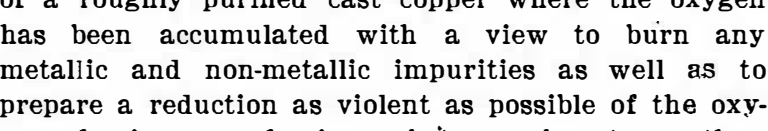

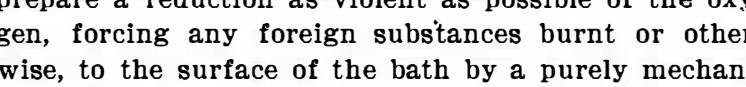

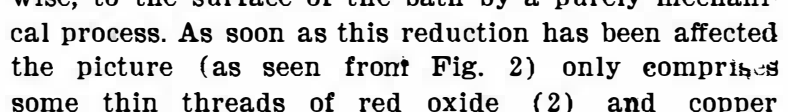

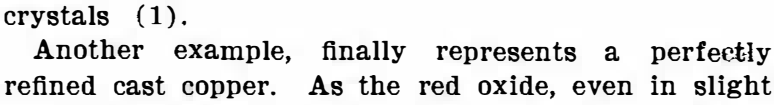
uantities, is detrimental to the mechanical and ele trical roperties of copper, the oxygen having once
done its datty, should be driven out completely. Th

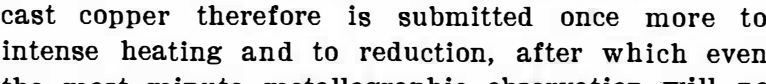

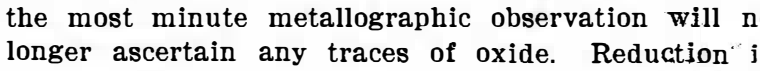

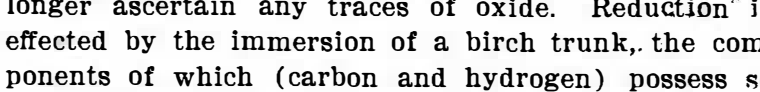
ponents of which (carbon and hydrogen p possess so
strons an aftrity tor oxygen that this elements sud

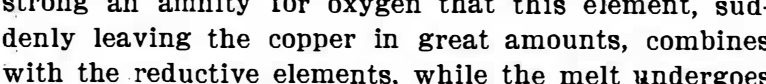
$a$ vilent seething

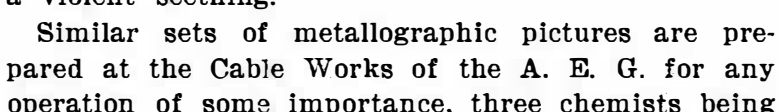

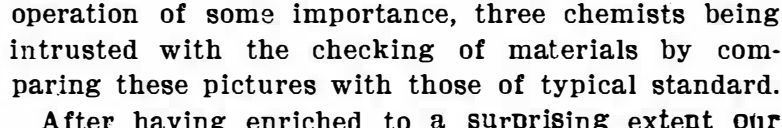
knomleage of Ilving organisms, the mitrosocope thus
promises to to render an entually yfficient assisitance to

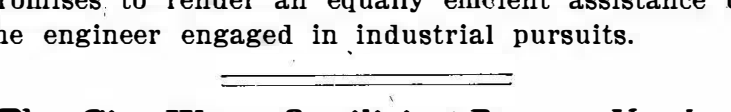
The City Water Sterilizing Process Used a

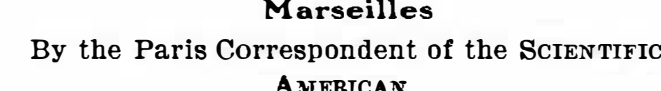

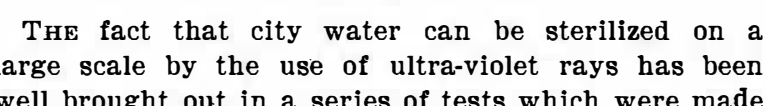
at Marseilles not l-10ng since. Owing to the knowledge
that the Durance River contains a large amount of

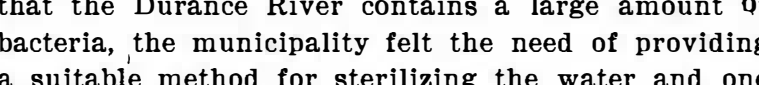
a suttable method tor steriliting the water and one
vhith should allow of a large delivery at the sam IIme. The results of the tests sem to show that
lae ultravioloter ray method is by tar the best

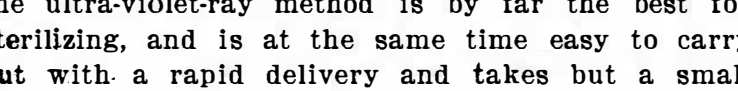

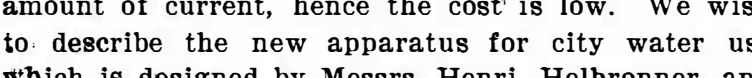

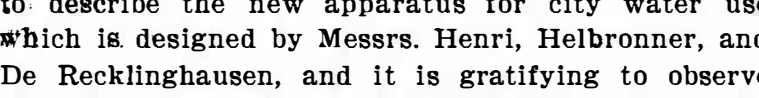
that the experiments a carried out by $\mathrm{y}$. Henri at the

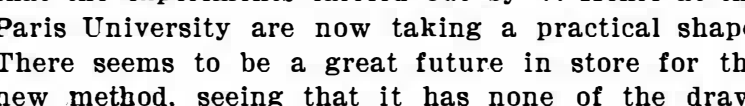
new method, seeing that it has none of the draw

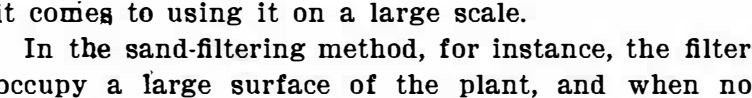

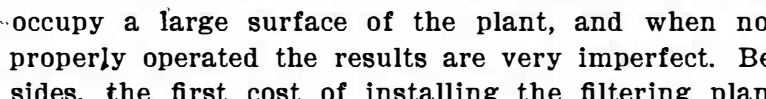

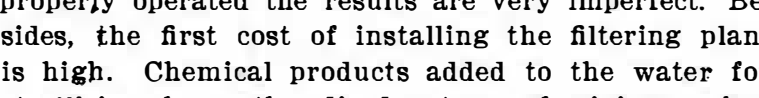

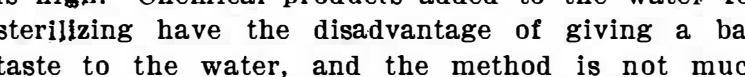

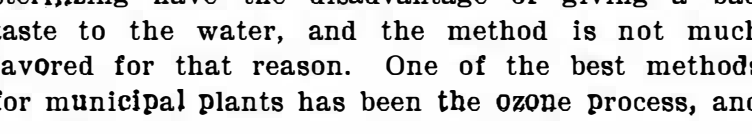

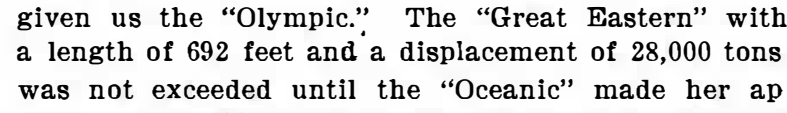

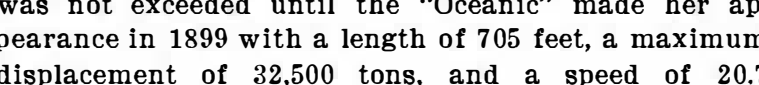

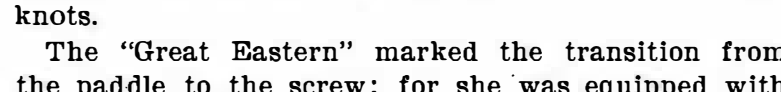

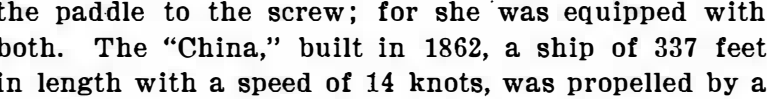

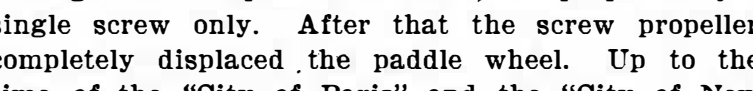

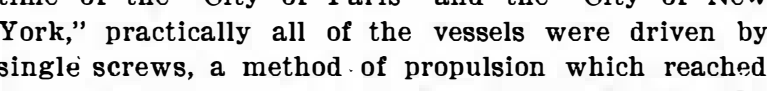

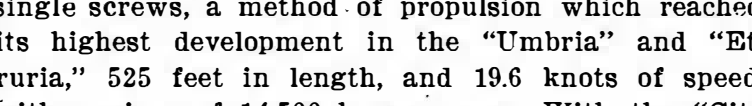

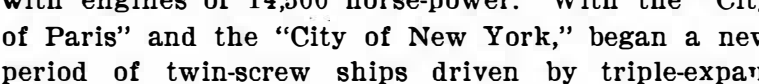

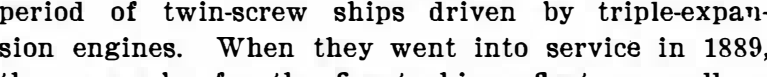

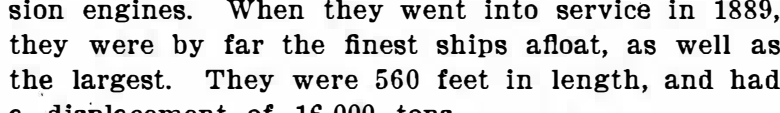

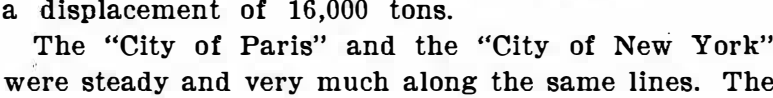
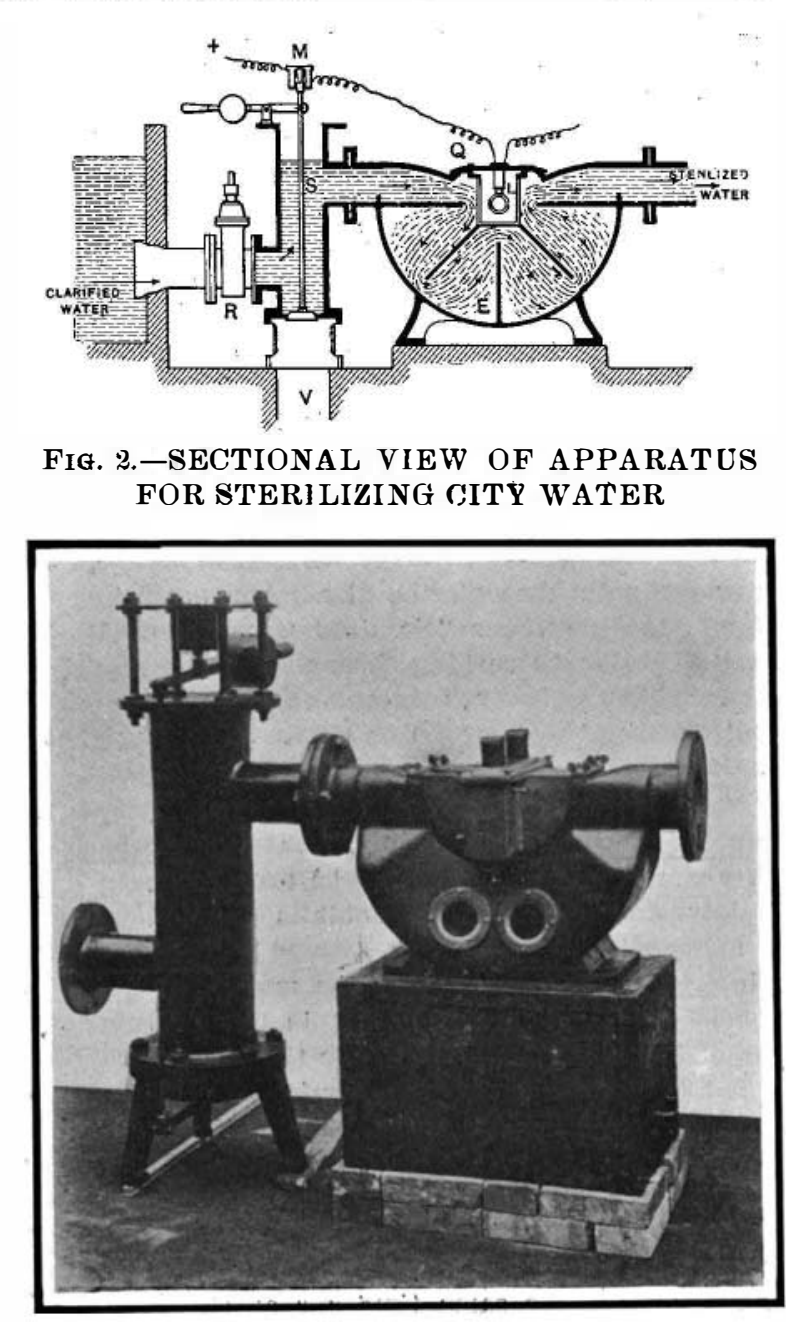

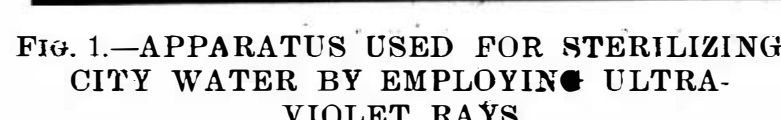

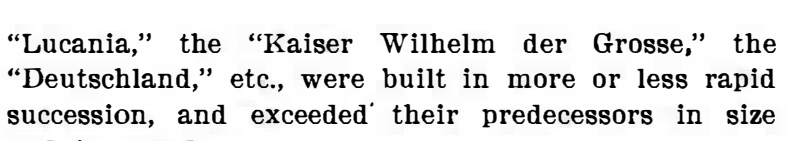

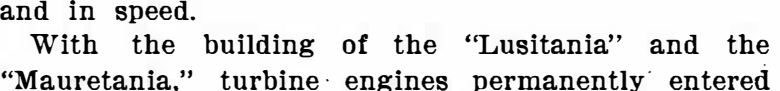

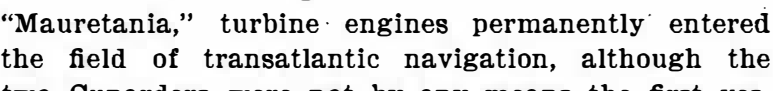

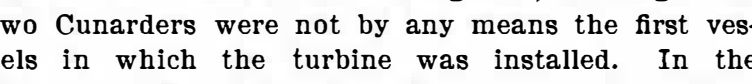
26 knots is maintaines steadily, but at a c cost which white star Line has made no effort to compotet with

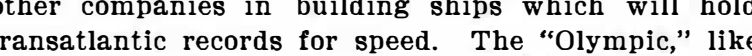

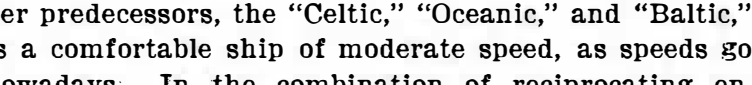
gines andi' turbinines she represents the entrance of a not a intele interesst.

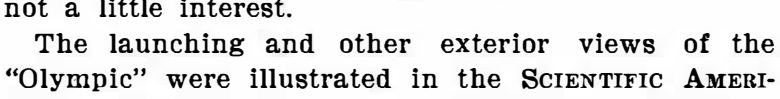

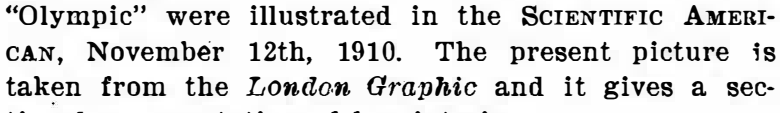

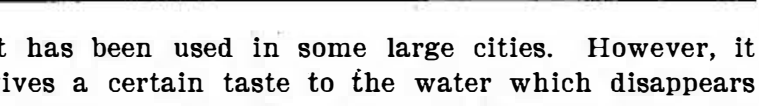

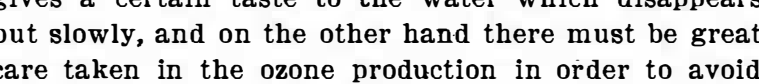

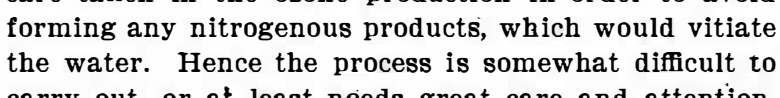

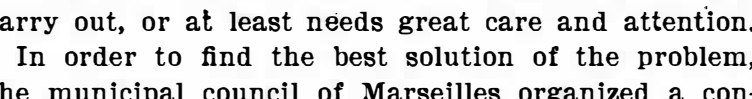

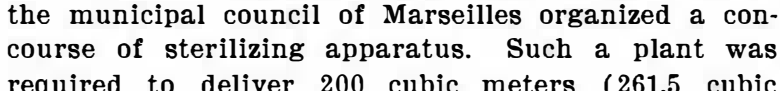

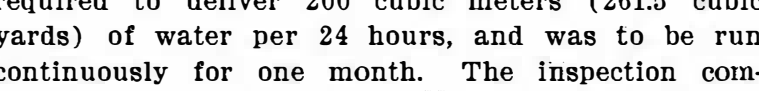

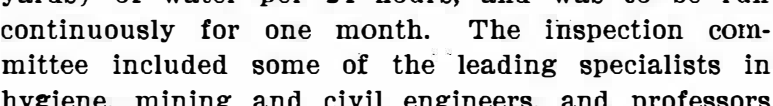

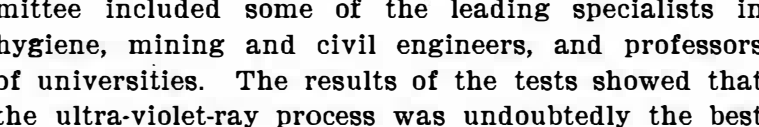

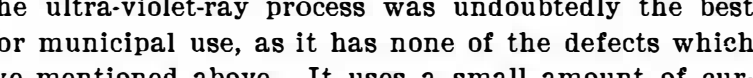

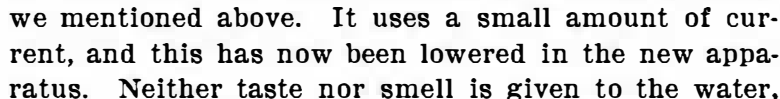

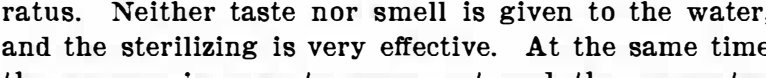

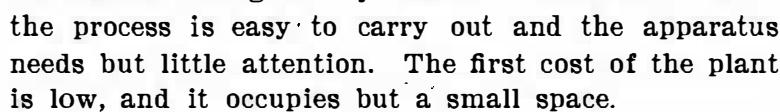

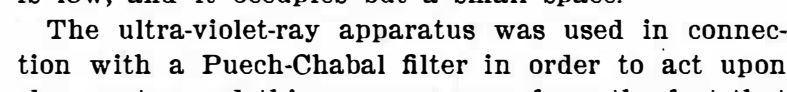
clear water, and this was necessary from the fact that
the Duvanace water is is very heavily charged with im-

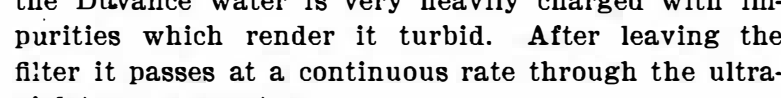

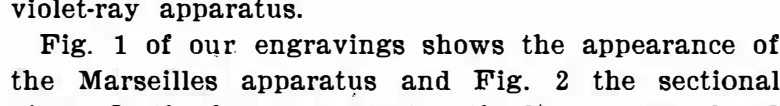

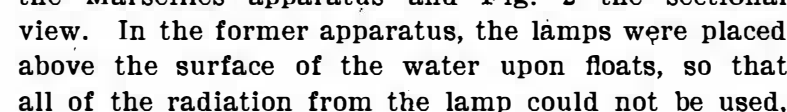

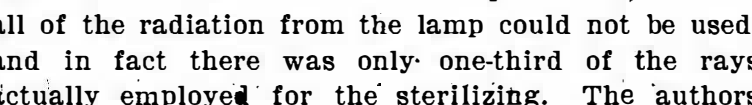

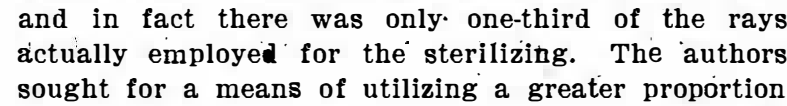

